\title{
CPT correlations for thermal properties of soils
}

\author{
P. J. Vardon ${ }^{1}$ (D) J. Peuchen ${ }^{2}$
}

Received: 20 February 2020 / Accepted: 12 July 2020/Published online: 24 July 2020

(C) The Author(s) 2020

\begin{abstract}
Obtaining in situ thermal properties of soils is often difficult and time-consuming. Here, cone penetration test (CPT) correlations are proposed and validated for thermal properties of saturated ground, i.e. thermal conductivity and volumetric heat capacity, giving continuous profiles of the parameters, in a substantially reduced time. The proposed correlations utilise the characteristics of existing CPT correlations. The volumetric heat capacity correlations show good agreement with laboratory hot disc tests, and the thermal conductivity correlations proved successful for a range of soil types, including organic soils, clays and sands, although with a reasonable scatter. Empirical adjustment was required for the thermal conductivity of soils showing high (normalised) cone resistance. Utilising thermal CPT (T-CPT)-derived thermal conductivity point values in conjunction with the thermal conductivity correlations offers accurate and continuous sitespecific profiles.
\end{abstract}

Keywords Correlations · CPT · Heat capacity $\cdot$ Thermal conductivity

\section{List of symbols}

$a \quad$ Fitting coefficient in Eq. (14)

A $\quad$ CPT coefficient defined in Eq. (7d)

$c_{p} \quad$ Specific heat capacity

C Volumetric heat capacity

$C_{x} \quad$ Volumetric heat capacity of soil component $x$

$f_{\text {solid }}$

$F_{\text {r }}$

$i \quad$ Counter for the solid components

$I_{c} \quad$ Soil behaviour-type index

$k \quad$ Thermal conductivity

$k_{x} \quad$ Thermal conductivity of $x$

$k_{\text {soil_orig }}$ Thermal conductivity from original relationship

$m \quad$ Stress exponent

$n \quad$ Porosity

$q_{\mathrm{n}} \quad$ Net cone resistance

$q_{t} \quad$ Corrected cone resistance

$P_{\mathrm{a}} \quad$ Atmospheric pressure
$Q_{\mathrm{tn}} \quad$ Normalised cone resistance

$Q_{\mathrm{tn} \_l i m} \quad$ Limit of $Q_{\mathrm{tn}}$ where CPT correlations overpredict thermal conductivity

ref Subscript relating to a reference point

$R^{2} \quad$ Coefficient of determination

RMSE Root mean square error

$S \quad$ Degree of saturation

$V_{\mathrm{s}} \quad$ Volume of solids

$V_{\mathrm{w}} \quad$ Volume of water

$V_{\mathrm{v}} \quad$ Volume of voids

$\beta \quad$ Fitting coefficient in Eq. (4)

$\gamma \quad$ Bulk unit weight

$\gamma_{\mathrm{w}} \quad$ Unit weight of water

$\gamma_{\mathrm{s}} \quad$ Unit weight of solid material

$\rho \quad$ Density

$\rho_{\mathrm{b}} \quad$ Bulk density

$\rho_{\mathrm{d}} \quad$ Dry density

$\sigma_{\mathrm{vo}} \quad$ In situ vertical total stress at cone base

$\sigma_{\mathrm{vo}}^{\prime} \quad$ In situ vertical effective stress at cone base

\section{P. J. Vardon}

P.J.Vardon@tudelft.nl

J. Peuchen

j.peuchen@fugro.com

1 Geo-Engineering Section, Delft University of Technology, PO Box 5048, 2600 GA Delft, The Netherlands

2 Fugro, PO Box 130, 2630 AC Nootdorp, The Netherlands

\section{Introduction}

The thermal properties of the ground are important for accurate design of shallow and deep geothermal systems, electricity cables, pipelines and other systems which 
involve heat transfer (e.g. [4, 21, 22, 26]). For many energy geostructures, e.g. energy piles and energy walls, or other heat emitting buried infrastructure, e.g. cables and pipelines, the depths between ground surface and several tens of metres are most interesting (e.g. [4, 7, 11, 22, 26]).

While this has been of interest for many years (e.g. $[8,18])$, there are still relatively few options of measuring or predicting thermal properties in situ. A number of laboratory test types exist (e.g. needle probe, double-needle probe or plane source), but as has been shown in Low et al. [22] and Vardon et al. [32], laboratory samples tend to exhibit different values than in situ tests, probably due to changes in density and saturation which occur as a result of sampling, sample handling and specimen preparation.

The commonly available in situ tests are the thermal response test (TRT), borehole geophysical logging methods, observation of in situ temperatures and various types of needle probes. The TRT involves heating a ground heat exchanger for a set period of time and monitoring the temperature evolution with time. Generally, this involves days-long tests and relatively expensive installation [22]. TRTs typically give a single value for the borehole in which they are installed; however, using distributed sensing, e.g. fibre optics, distributed values of thermal conductivity can be estimated (e.g. [33]). Borehole geophysical logging methods require an open borehole and are not proven at depths of less than $\sim 200 \mathrm{~m}$ below ground surface [25]. Generally, in situ temperature methods have been shown to work only at several tens of metres below ground surface and only where investigation of heat flux from deep boreholes is available [25]. However, some methods have been developed using close to surface environmental signals. These methods require long-term measurements of temperature at different levels within the soil where the thermal conductivity is required (e.g. [9]). In situ needle probes of any significant depth require intrusive methods such as self-weight penetration, controlled push, vibratory driving or tight-fit predrilling. In situ test times are typically in the order of $20 \mathrm{~min}$ for a single data point and a needle with a diameter in the order of $10 \mathrm{~mm}$ (e.g. [12]). In the majority of the tests above, the heat capacity of the soil is not obtained.

Following from the suggestion and initial methodology to derive in situ thermal properties from a thermal dissipation test using a cone penetration test (CPT), the thermal cone penetration test (T-CPT) [2], a robust and physically accurate method was derived and validated for thermal conductivity by Vardon et al. [32]. This method gives point-wise values that can be taken at a number of depths, to give a pseudo-continuous profile. The time required for each point is around $400 \mathrm{~s}$. However, as the temperature increase in the test is derived from friction between the tool and the soil, the spatial resolution is limited, i.e. sufficient space between readings is required to allow heat generation in the penetrometer. The temperature data required to determine the volumetric heat capacity data were shown by Vardon et al. [32] to be in the first few seconds of the test and therefore would implicitly have a lower quality.

This paper proposes and tests two CPT correlations for thermal conductivity, $k$, and volumetric heat capacity, $C$, for saturated soils. These are based on previously developed correlations for soil density by Robertson and Cabal [29] and Lengkeek et al. [20]. The new correlations for thermal conductivity are therefore named $\mathrm{k}-\mathrm{CPT}_{R}$ and $\mathrm{k}^{-\mathrm{CPT}_{L}}$, based on the Robertson and Cabal [29] and Lengkeek et al. [20] density correlations, respectively, and the two correlations for volumetric heat capacity of soil are named C-CPT ${ }_{R}$ and C-CPT ${ }_{L}$. The correlations link the data typically collected via CPTs (cone resistance, sleeve friction and pore pressure) to other properties. These give continuous profiles, and the input data are also typically taken as part of site investigation for many geotechnical projects. The speed of recording is fast $(20 \mathrm{~mm} / \mathrm{s})$. Validation via both field and laboratory tests is presented, and an empirical adjustment is needed for the thermal conductivity correlations where high cone resistance is encountered.

The CPT correlations have been applied as part of substantial site investigations in the North Sea enabling the development of offshore wind farms (e.g. [24]).

\section{Heat capacity and thermal conductivity of soils}

Soils and geomaterials are composed of a mixture of solid particles of different minerals, water and air. The approximate thermal properties of the various soil components are shown in Table 1 , at atmospheric pressure and at $20^{\circ} \mathrm{C}$. It can be observed that the salinity of water $(35 \mathrm{~g} / \mathrm{l}$ is approximately seawater) makes no significant difference to any of the properties, although higher concentrations do [1]. Within the temperatures considered in CPTs, i.e. between $\sim 10$ and $\sim 30{ }^{\circ} \mathrm{C}$, these are considered to be constant.

The volumetric heat capacity is a volumetric property, which means that it is reasonable to use a weighted arithmetic mean for the volumetric heat capacity. In contrast, the thermal conductivity is a directional material property which defines the resistance to a flux. As a soil cannot be conceptualised as a set of thermal resistors in series nor in parallel, which would require a weighted arithmetic or weighted harmonic mean, respectively, it is reasonable to use a geometric mean for the thermal conductivity [8] which provides an intermediate result. It is noted that there 
Table 1 Thermal properties of soil components at $20{ }^{\circ} \mathrm{C}$ and atmospheric pressure (after $[5,8,13,31]$ )

\begin{tabular}{lllll}
\hline Soil component & $\begin{array}{l}\text { Thermal conductivity }[k(\mathrm{~W} / \\
\mathrm{m} \mathrm{K})]\end{array}$ & $\begin{array}{l}\text { Specific heat capacity }\left[c_{p}(\mathrm{~J} /\right. \\
\mathrm{kg} \mathrm{K})]\end{array}$ & $\begin{array}{l}\text { Density }[\rho(\mathrm{kg} / \\
\left.\left.\mathrm{m}^{3}\right)\right]\end{array}$ & $\begin{array}{l}\text { Volumetric heat capacity }\left[C=c_{p} \rho\right. \\
\left.\left(\mathrm{MJ} / \mathrm{m}^{3} \mathrm{~K}\right)\right]\end{array}$ \\
\hline $\begin{array}{llll}\text { Water (pure) } \\
\text { Water (saline- }\end{array}$ & 0.6 & 4148 & 997 & 4.140 \\
$\quad 0.6$ & 3986 & 1024 & 4.082 \\
Air & & & & 0.012 \\
Clay mineral & 2.9 & 995 & 12 & 2.120 \\
Sand (quartz) & 8.4 & 800 & 2650 & 1.940 \\
Silt & 2.9 & 730 & 2660 & 2.120 \\
Peat (organic & 0.25 & 800 & 2650 & 2.500 \\
$\quad$ matter) & & 1920 & 1300 &
\end{tabular}

have been many models for the thermal conductivity proposed (see [10,17] for a comprehensive overview).

Following an arithmetic mean for the volumetric heat capacity and a geometric mean for the thermal conductivity gives the following relations [8]:

$C_{\text {soil }}=(1-n) \sum_{i} f_{\text {solid }, i} C_{\text {solid }, i}+n S C_{\text {water }}+n(1-S) C_{\text {air }}$

$k_{\mathrm{soil}}=\left(\prod_{i} k_{\mathrm{solid}, i}^{(1-n) f_{\text {solid }, i}}\right)\left(k_{\mathrm{water}}^{n S} k_{\mathrm{air}}^{n(1-S)}\right)$

where $n$ is the porosity of the soil, $i$ is a counter for the solid components, $f_{\text {solid }}$ is the fraction by volume of the solid component and $S=V_{\mathrm{w}} / V_{\mathrm{v}}$ is the degree of saturation (ratio of volume of water to volume of voids in the soil). The subscript solid refers to different solid soil components, i.e. quartz, clay minerals, silt or organic matter. In Eq. (1) the contribution of the air term is small and can be reasonably neglected; in Eq. (2) the air term is almost 1 at high degrees of saturation and can be neglected. For the rest of this paper, the degree of saturation is considered to be equal to 1, i.e. a saturated soil, and the correlations developed are considered only for these conditions. In principle, ice could be added into Eqs. (1) and (2) [8], although in this paper the ice content is not considered further. While CPTs are used in frozen soils [15, 23], they are not frequently used to identify ice content. It is noted that both the heat capacity and the thermal conductivity of ice are significantly different to that of water.

Figure 1 presents both the thermal conductivity and volumetric heat capacity for saturated sand and clay mixtures with a wide range in density (range of porosity is $0.1-0.9$, corresponding to a range in dry density from 2390 to $266 \mathrm{~kg} / \mathrm{m}^{3}$ ), using the component values from Table 1 and Eqs. (1) and (2). It is seen that the variation with clay/ sand fraction is very small for the volumetric heat capacity, but large for the thermal conductivity. An experimental campaign [32] measuring the thermal conductivity has been compared to the calculated values. The measurements were derived from a number of different methods, with the density calculated directly in the laboratory and via a correlation to the T-CPT measurements (correlation reported in the next section [29]). It is seen in Fig. 1b that the calculated values coincide well with the range of predicted values, observed by the experimental data overlapping the calculated thermal conductivities for the typical range of observed porosities/dry densities.

\section{Existing CPT correlations for density}

CPT correlations are able to determine soil behaviour type and density with a reasonable accuracy (e.g. [20, 29], who report coefficient of determination $\left(R^{2}\right)$ values of up to 0.88 for density). The variation in the volumetric heat capacity of different soil minerals is significantly lower than the thermal conductivity (Table 1). This implies that the volumetric heat capacity would be better suited to back-calculation via CPT correlations for density than the thermal conductivity, as the identification of different soil minerals is not needed. However, as CPT correlations are able to distinguish between different types of soil, albeit the behaviour type not composition directly, a good estimate can be proposed.

A well-known correlation for soil density (presented in terms of a unit weight ratio) by Robertson and Cabal [29] is:

$\frac{\gamma}{\gamma_{\mathrm{w}}}=0.27 \log F_{\mathrm{r}}+0.36 \log Q_{\mathrm{tn}}+1.236$

where $\gamma$ is the bulk unit weight, $\gamma_{\mathrm{w}}$ is the unit weight of water, $Q_{\mathrm{tn}}$ is the normalised cone resistance and $F_{\mathrm{r}}$ is the normalised friction ratio. $Q_{\mathrm{tn}}=\left[\left(q_{t}-\sigma_{\mathrm{vo}}\right) / P_{\mathrm{a}}\right]\left(P_{\mathrm{a}} / \sigma_{\mathrm{vo}}^{\prime}\right)^{m}$, where $q_{t}$ is the corrected cone resistance, $\sigma_{\mathrm{vo}}$ is the in situ 
(a)

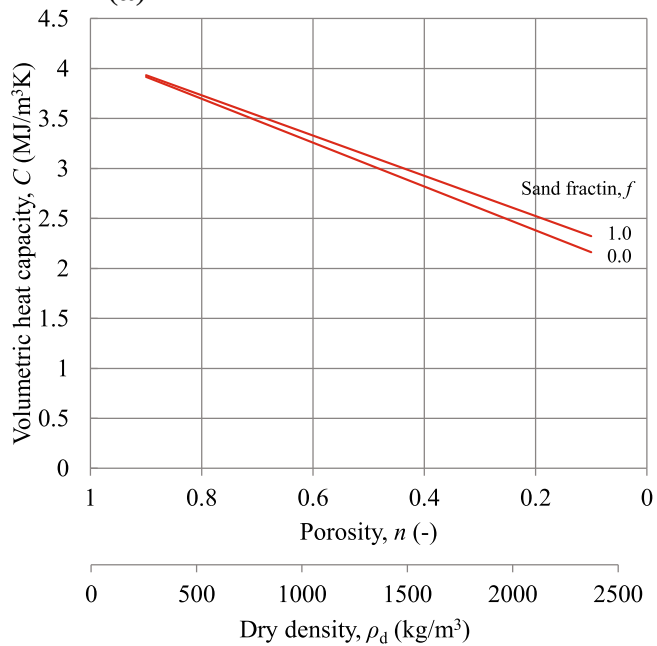

(b)

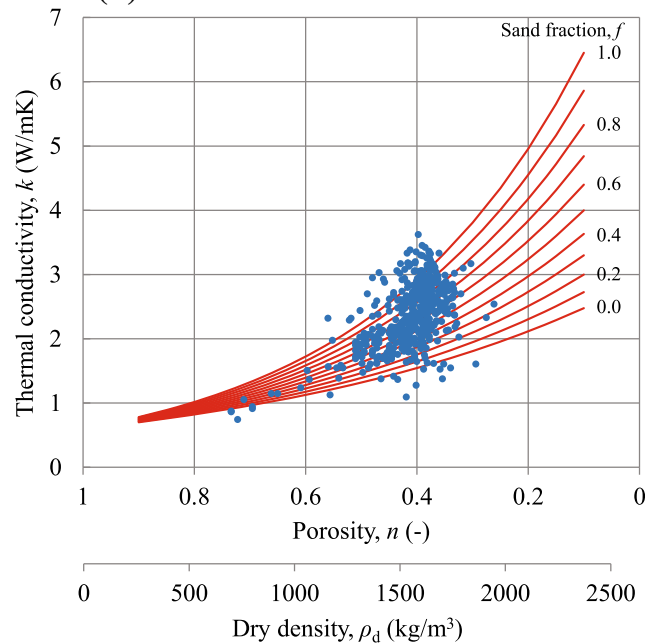

Fig. 1 Calculated a volumetric heat capacities and $\mathbf{b}$ thermal conductivities for sand/clay mixtures. Blue dots are from an experimental campaign [32] (color figure online)

vertical total stress at the cone base (base of conical part of the cone penetrometer), $\sigma_{\mathrm{vo}}^{\prime}$ is the in situ vertical effective stress at the cone base, $P_{\mathrm{a}}$ is the atmospheric pressure and $m$ is a stress exponent related to the soil type. $F_{\mathrm{r}}=$ $100 \cdot f_{t} / q_{\mathrm{n}}(\%)$ where $f_{t}$ is the corrected sleeve friction and $q_{\mathrm{n}}$ is the net cone resistance $\left(q_{t}-\sigma_{\mathrm{vo}}\right)$.

For soils with organic content, the Lengkeek et al. [20] correlation for bulk density can be used, rewritten in the same units as Eq. (3):

$\frac{\gamma}{\gamma_{\mathrm{w}}}=\frac{\gamma_{\text {ref }}}{\gamma_{\mathrm{w}}}-\beta \frac{\log \left(\frac{Q_{\mathrm{tn}, \mathrm{ref}}}{Q_{\mathrm{tn}}}\right)}{\log \left(\frac{F_{\mathrm{r}, \text { ref }}}{F_{\mathrm{r}}}\right)}$

where the subscript ref relates to a reference point and $\beta$ controls the inclination of equal weight contours. The default parameter values are $\gamma_{\text {ref }}=19 \mathrm{kN} / \mathrm{m}^{3}, Q_{\mathrm{tn}, \mathrm{ref}}=50$, $F_{\text {r.ref }}=30$ and $\beta=0.412$, which are the parameter values that best fit the database of soils used by Lengkeek et al. [20]. In further equations, these parameters are used as constants in the equations-any site-specific modifications in these parameters must then be included into the derivation of the equations in the following section, i.e. the derivation process must be followed but using the sitespecific parameters. Based on the work of Lengkeek et al. [20], there are significant improvements in the fit below a unit weight ratio of 1.5 , with more minor improvements above a unit weight ratio of approximately 1.5 when compared to the Robertson and Cabal [29] correlation. The coefficient of determination $\left(R^{2}\right)$ value is reported by Lengkeek et al. [20] to increase from 0.49, when using the Robertson and Cabal [29] correlation, to 0.88 when using their proposed correlation, although this is impacted by the selection of the soil database, as the relationship is structurally better for less dense soils. The densities calculated using these correlations for a CPT database used later in this paper are comparable, except where organic material is present.

\section{Proposed CPT correlations for heat capacity and thermal conductivity}

Recognising that the volumetric heat capacity is not sensitive to the mineral type (i.e. either clay or sand, see Table 1), and inserting values for the specific heat capacity of the water and soil minerals from Table 1, Eq. (1) can be rewritten as:

$C_{\text {soil }}=2(1-n)+4.14 n=2+2.14 n$

By combining Eqs. (3) and (5), using the identity $\gamma / \gamma_{\mathrm{w}}=$ $n+\gamma_{\mathrm{s}} / \gamma_{\mathrm{w}}(1-n)$ and $\gamma_{\mathrm{s}} / \gamma_{\mathrm{w}}=2.65$ (see Table 1 , where $\gamma_{\mathrm{s}}$ is the unit weight of solid material) leads to a new proposed correlation for the volumetric heat capacity, named the C$\mathrm{CPT}_{R}$ correlation, also shown graphically in Fig. 2:

$C_{\text {soil }}=-0.350 \log F_{\mathrm{r}}-0.467 \log Q_{\mathrm{tn}}+3.834$

Note that the volumetric heat capacity increases as the density decreases, due to the large specific heat capacity of water. This trend is opposite for the thermal conductivity. This relation cannot be used for soils with a substantial organic matter content, as illustrated by Lengkeek et al. [20] where the correlation deviates from experimentally found results for unit weight ratios below 1.5. In Fig. 2, the relationship is not drawn over soil behaviour types 1,8 and 9 , as these soils are highly affected by their microstructure and the densities predicted by [29] fall outside typically observed soils. 


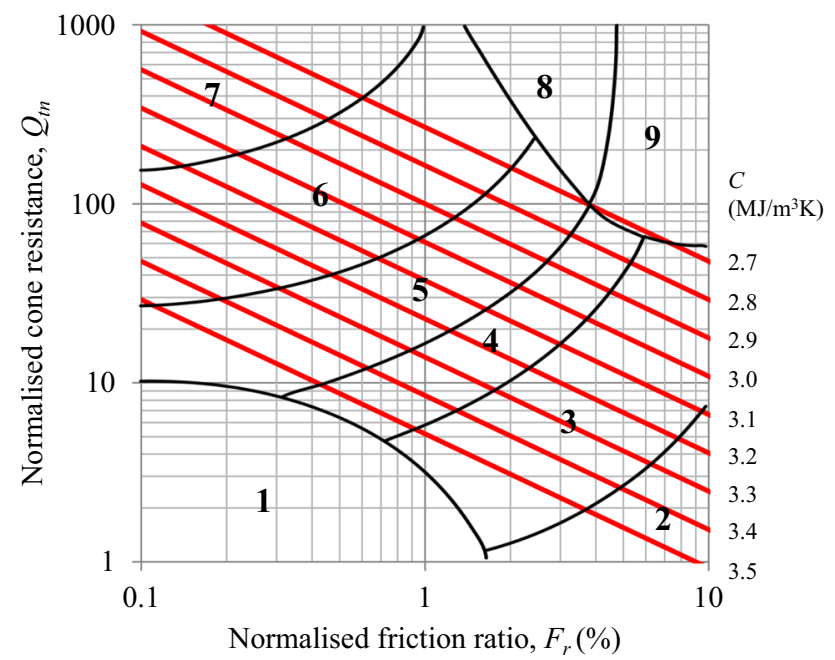

Fig. 2 C-CPT ${ }_{R}$ correlation for volumetric heat capacity. Black lines are the boundaries of different soil behaviour types, as defined by Robertson [27]. The numbers in the zones represent different soil behaviour types: 1 sensitive fine grained; 2 organic material; 3 clay to silty clay; 4 clayey silt to silty clay; 5 silt clay to sandy silt; 6 clean sand to silty sand; 7 gravelly sand to sand; 8 very stiff sand to clayey sand; and 9 very stiff fine grained (color figure online)

The same substitutions can be made as in Eqs. (5) and (6) for either sand/clay or organic material, which have different values of heat capacity and density (see Table 1). Equation (7a) is the result for materials with a porosity $n<0.7$ or $\frac{\gamma}{\gamma_{\mathrm{w}}}>1.5$, with the assumption that there is no organic matter. Equation $(7 \mathrm{c})$ assumes that the material is only composed of organic matter at $n>0.83$ or $\frac{\gamma}{\gamma_{w}}<1.05$. A linear interpolation between these two solutions is made, for materials composed of both clay/sand and organic matter, found in Eq. (7b).

$A<0.4 ; \quad C_{\text {soil }}=2.963+1.30 A$

$0.4<A<0.85 ; \quad C_{\text {soil }}=2.945+1.34 A$

$A>0.85 ; \quad C_{\text {soil }}=3.238+A$

where

$A=0.412 \frac{\log \left(\frac{50}{Q_{\mathrm{tn}}}\right)}{\log \left(\frac{30}{F_{\mathrm{r}}}\right)}$

where $A$ is the second term in Eq. (4), including the default parameters, which is used to define the proportion of organic material in the soil. Note again that if site-specific modifications have been used in Eq. (4), these must be included in this derivation.

This relationship, named the $\mathrm{C}-\mathrm{CPT}_{L}$ correlation, is presented in Fig. 3.

For the thermal conductivity, again first for non-organic soils, based on the Robertson and Cabal unit weight

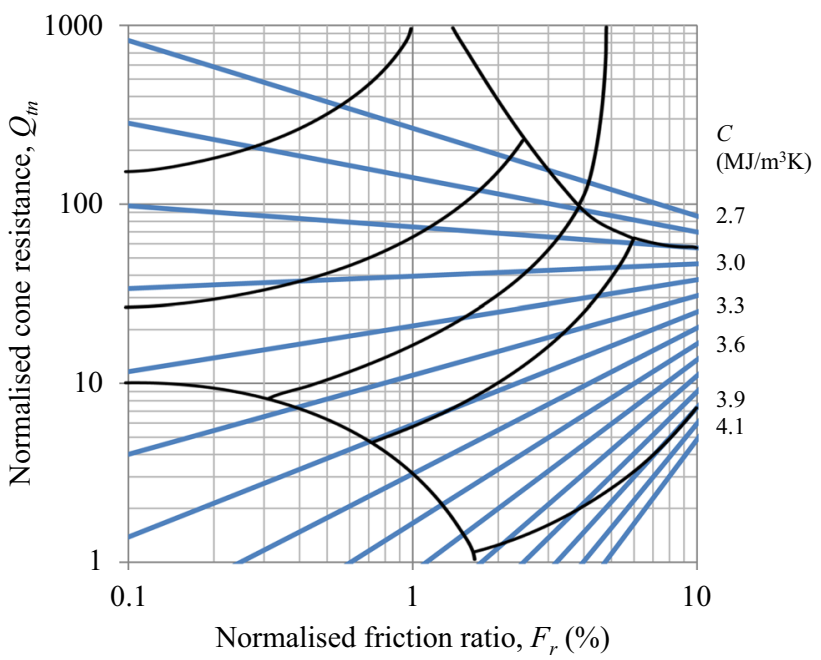

Fig. 3 C-CPT ${ }_{L}$ correlation for volumetric heat capacity. Black lines are the boundaries of different soil behaviour types, as defined by Robertson [27], see Fig. 2 for more details (color figure online)

relation, Eq. (2) can be written, with substitutions of values from Table 1, as:

$k_{\text {soil }}=2.9^{(1-n)\left(1-f_{\text {sand }}\right)} 8.4^{(1-n) f_{\text {sand }}} 0.6^{n}$

where

$n=-0.164 \log F_{\mathrm{r}}-0.218 \log Q_{\mathrm{tn}}+0.857$

The fraction of sand, $f_{\text {sand }}$, can be estimated making use of the soil behaviour-type index $I_{c}$ value [16], which is used to separate soils of a certain behaviour type. This can be plotted on a normalised soil behaviour-type chart (SBTn). The $I_{c}$ values approximate the black lines shown in Figs. 2, 3 and 4 and are the dotted-dash lines in Fig. 4a. The zones of soil behaviour type are numbered from 2 to 7 from the bottom right to the top left (Fig. 2). Assuming that the sand fraction increases from zero in SBTn zone 2 to 1 in SBTn zone 7, we yield the values in Table 2 and via interpolation, Eq. (10).

$f_{\text {sand }}=1.77-0.453 I_{c} ; \quad 0<f_{\text {sand }}<1$

Equations (8)-(10) form the $\mathrm{k}-\mathrm{CPT}_{R}$ correlation.

Using again the Lengkeek et al. [20] relation for soils with organic material, Eq. (2) can be written:

$k_{\text {soil }}=2.9^{(1-n)\left(f_{\text {clay }}\right)} 8.4^{(1-n) f_{\text {sand }}} 0.25^{(1-n) f_{\text {organic }}} 0.6^{n}$

where

$f_{\text {organic }}=\frac{(A-0.4)}{0.45} ; \quad 0<f_{\text {organic }}<1$

$f_{\text {clay }}=1-f_{\text {organic }}-f_{\text {sand }} ; \quad 0<f_{\text {clay }}<1$

and the porosity is again defined in three zones, delineated by $A$ (Eq. $7 \mathrm{~d}$ ) again based on the amount of organic matter, as: 
(a)

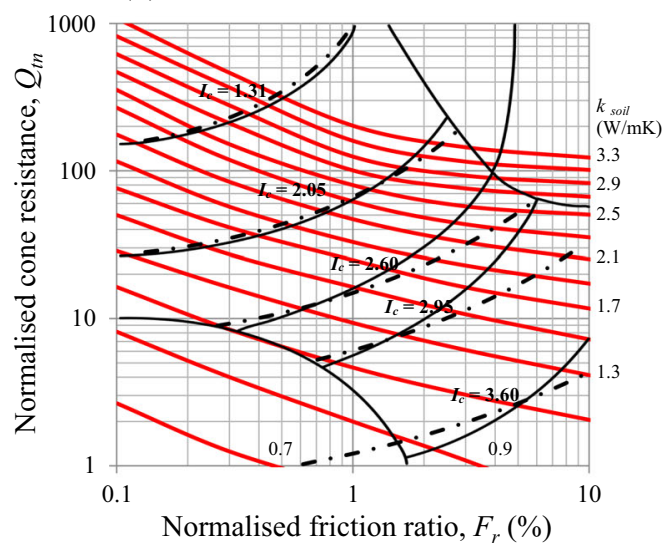

(b)

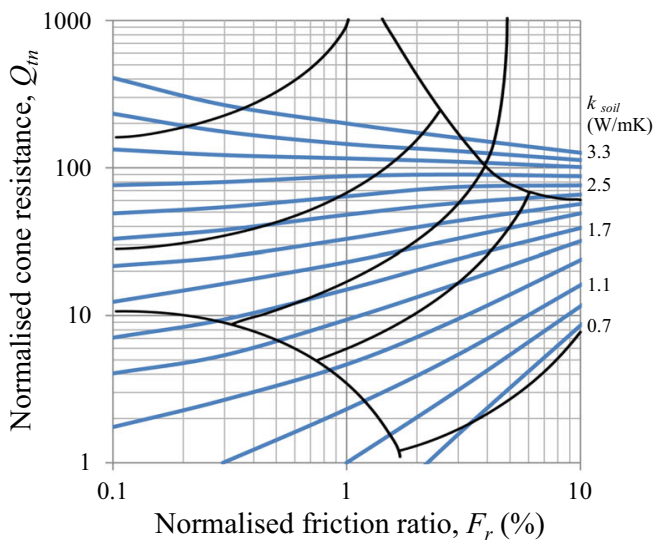

Fig. 4 Theoretical part of proposed thermal conductivity correlations a k-CPT $\mathrm{C}_{R} ; \mathbf{b} \mathrm{k}-\mathrm{CPT}_{L}$. Black lines are the boundaries of different soil behaviour types, as defined by Robertson [27], see Fig. 2 for more details. The dot-dash lines in (a) represent $I_{c}$ values approximating the boundaries between soil behaviour-type zones

Table 2 Parameters for linear relation between sand fraction and $I_{c}$

\begin{tabular}{llll}
\hline SBTn zone & Upper boundary, $I_{c}$ & Lower boundary, $I_{c}$ & Approximate average sand fraction, $f_{\text {sand }}$ \\
\hline 2 & - & 3.6 & 0 \\
3 & 3.6 & 2.95 & 0.25 \\
4 & 2.95 & 2.6 & 0.5 \\
5 & 2.6 & 2.05 & 0.75 \\
6 & 2.05 & 1.31 & 1.0 \\
\hline
\end{tabular}

$A<0.4 ; \quad n=0.45+0.606 A$

$0.4<A<0.85 ; \quad n=0.58+0.3 A$

$A>0.85 ; \quad n=-2+3.33 A$

Equations (11)-(13c) form the $\mathrm{k}-\mathrm{CPT}_{L}$ correlation.

Figure 4 shows the theoretical part of the $\mathrm{k}-\mathrm{CPT}_{R}$ correlation and the $\mathrm{k}_{-} \mathrm{CPT}_{L}$ correlation. An empirical part of the correlations is given in Sect. 5, for the situation at high cone resistance where these theoretical relations were shown not to match experimental results.

CPT correlations are empirical, and where extensive site investigations show that density is better represented by local or site-specific correlations, the procedure shown here can be utilised to achieve local thermal property correlations. If local thermal properties are measured in situ, again these correlations can be improved.

\section{Validation}

Both a field campaign and laboratory tests were carried out. As part of this field campaign, five CPTs were performed and samples were collected to be tested in the laboratory.
Additionally, records of two CPTs were used from an existing database (one of which had samples in store which could be tested). The soil profiles are shown schematically in Fig. 5. For the five newly collected CPTs, all were subsea and within several hundred metres of each other. Both of the CPTs obtained from a database were onshore. In all seven of the CPTs, several T-CPT dissipation tests had

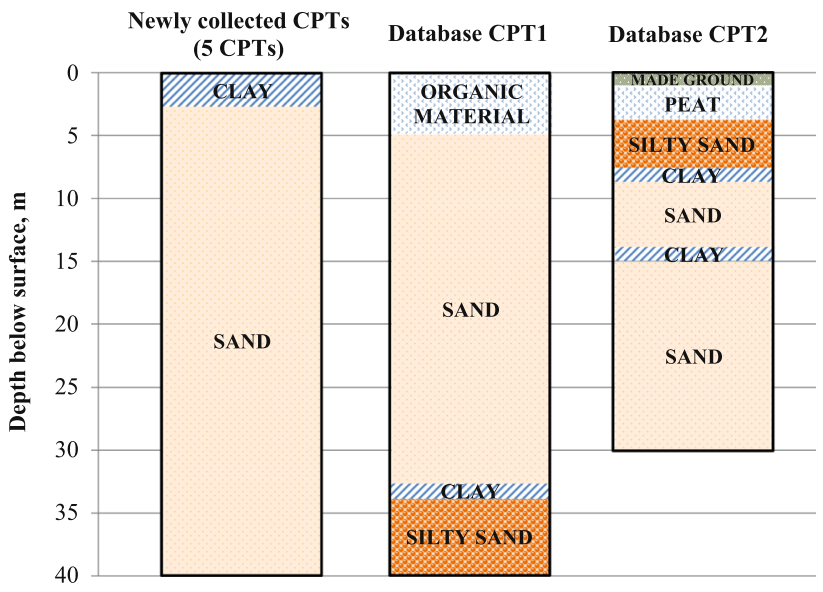

Fig. 5 Soil profiles of the CPT database 
been performed, so that thermal conductivity measurements were available.

Two types of laboratory testing were undertaken, the first using a needle probe (KD2 Pro Decagon with a singleneedle attachment used for the thermal conductivity and a dual-needle attachment used for the volumetric heat capacity [6]), and the second using hot disc tests [30]. As the double-needle probe used was small $(30 \mathrm{~mm}$ long needles, $1.3 \mathrm{~mm}$ diameter, $6 \mathrm{~mm}$ spacing), and mainly sands were tested, results were considered less reliable than results for the hot disc tests, due to the lower amount of particles in contact with the small needles, and therefore more variability. Needle probe tests were carried out following ASTM D5334-14 [3], and hot disc tests were carried out following ISO 22007-2 [14].

In Fig. 6 the comparison of the CPT correlation and hot disc tests is made, with the ' $R$ ' indicating the results for the $\mathrm{C}-\mathrm{CPT}_{R}$ correlation and the ' $L$ ' indicating the C-CPT $L$. The CPT record from the same depth as the sample was used; no local averaging was applied. In Fig. 6a, the raw data from the hot disc tests are compared, though it is observed that the densities at which the testing was done were different. This resulted in reasonably high RMSE values and $R^{2}$ values of $\sim 0.07$ for both correlations. Note that the $R^{2}$ values severely affected by the limited data range. In Fig. $6 \mathrm{~b}$ the volumetric heat capacity from the hot disc tests is modified via Eq. (5) to correct for different densities recorded after the laboratory tests and estimated via correlations with CPT data (i.e. $C_{\text {soil,corr }}=C_{\text {soil,meas }}+2.14 \Delta n$, where $\Delta n$ is the difference in porosity between the in situ soil and the tested soil and the subscripts corr and meas indicate the corrected and measured values, respectively). The porosity was calculated for the CPT data using the density correlations presented in Sect. 3 and again using the identity $\gamma / \gamma_{\mathrm{w}}=n+\gamma_{\mathrm{s}} / \gamma_{\mathrm{w}}(1-n)$ and $\gamma_{\mathrm{s}} / \gamma_{\mathrm{w}}=2.65$ (see Table 1). The open symbols are for a clay material, undertaken to widen the range of material used. The densities at which the hot disc tests were undertaken for the soils represented by the open symbols were not measured and were estimated as the average of the other tests (the others were measured), as the experimental procedure involved adding a similar mass of material into a mould. It is seen in Fig. 6b that a good agreement is found [demonstrated by a low root mean square error (RMSE)] and a close proximity to the 1:1 line shown in black, with only little variation. The $R^{2}$ values for both correlations increase to $\sim 0.7$, indicating a strong correlation. Doubleneedle laboratory tests were also carried out, but were observed to be less reliable than hot disc tests. The doubleneedle laboratory tests showed a RMSE of around 0.5 when compared to the CPT correlation.

The thermal conductivity values predicted by CPT correlation and derived from laboratory test data are compared in Figs. 7 and 8. In Fig. 7, the laboratory test data (needle probe) show slightly lower values, with a reasonable spread. The $R^{2}$ values are 0.2 and 0.07 for the $\mathrm{k}-\mathrm{CPT}_{R}$ and $\mathrm{k}-\mathrm{CPT}_{L}$ correlations, respectively, with the limited range of data limiting the values. As noted in Vardon et al. [32], laboratory testing often resulted in lower results than in situ testing, probably due to lower densities or water drainage (air in soil).

One limitation is that the soil tested in Figs. 6 and 7 is sand, and further validation against a wider range of soils is needed. In Fig. 6, the results from the two volumetric heat capacity correlations exhibit only slight differences in the results, as expected for soils without organic material. This is also seen in Fig. 7 for the thermal conductivity correlation results.
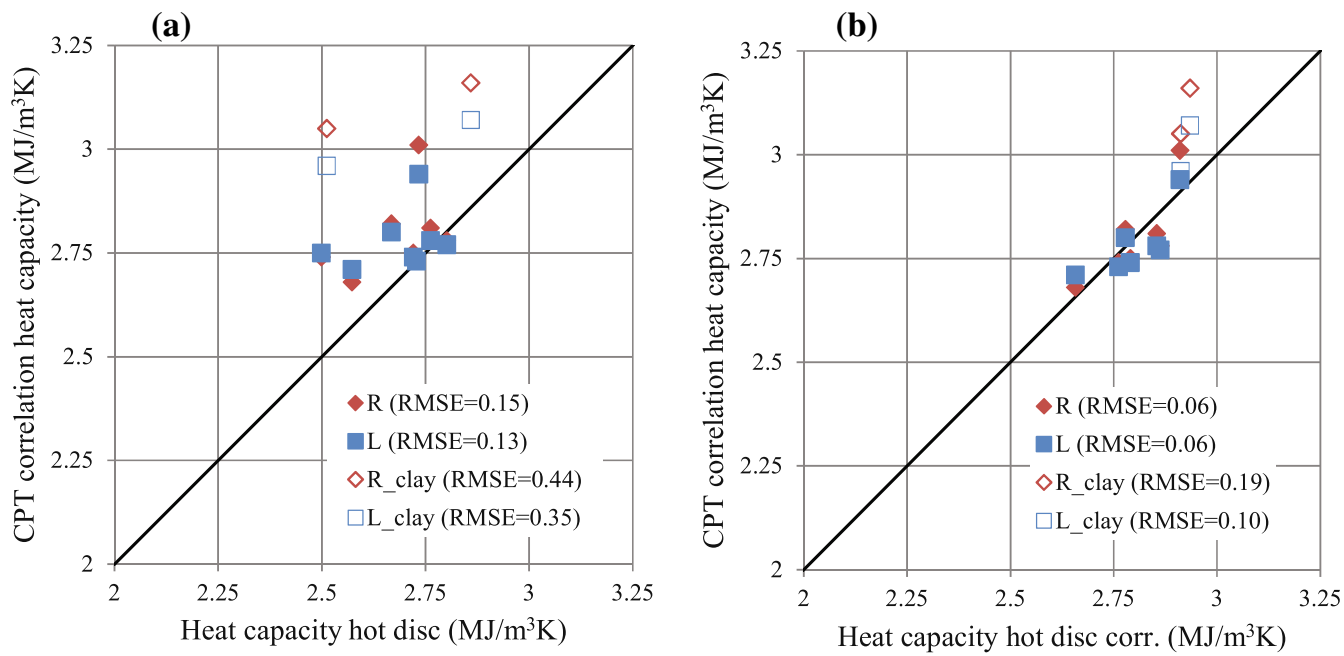

Fig. 6 Comparison of volumetric heat capacity derived from C-CPT $x$ correlations (where $x$ refers to either $R$ or $L$ in the legend) and laboratory hot disc test data $\mathbf{a}$ original data and $\mathbf{b}$ data corrected for dry density 


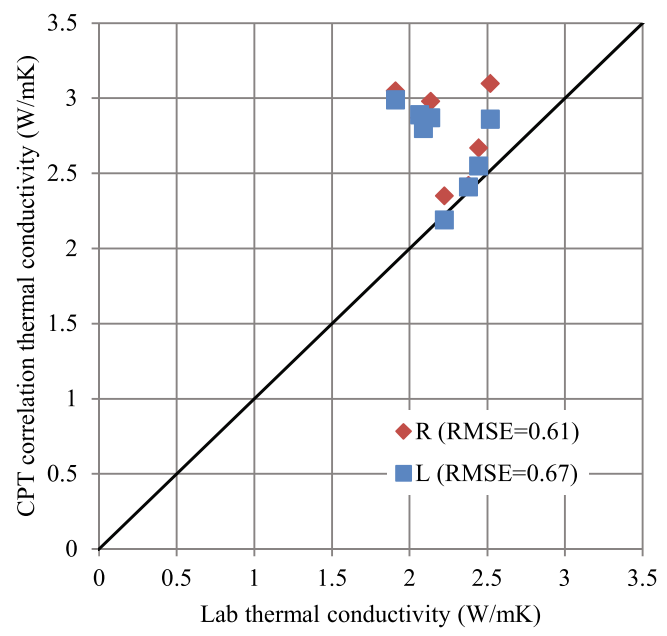

Fig. 7 Comparison of thermal conductivity derived from the theoretical parts of the $\mathrm{k}-\mathrm{CPT}_{x}$ correlations (where $x$ refers to either $R$ or $L$ in the legend) and laboratory needle test data

In Fig. 8, T-CPT dissipation test data (validated in Vardon et al. [32]) were used, and this meant significantly more data points were available, and importantly, in situ data. A wider range of values were available as the two CPTs taken from the database had tested different soil layers. It can be seen that the results are good at all of the ranges of thermal conductivity, except at the highest thermal conductivities predicted by both the CPT correlations. It is noted that the results are similar with both the CPT correlations. The $R^{2}$ values are 0.63 and 0.74 for the $\mathrm{k}-\mathrm{CPT}_{R}$ and $\mathrm{k}-\mathrm{CPT}_{L}$ correlations, respectively.

Based on an error analysis of thermal conductivity against $Q_{\mathrm{tn}}$ and $F_{\mathrm{r}-}$, a linear relationship between the log of $Q_{\mathrm{tn}}$ (above $Q_{\mathrm{tn}} \approx 170$ ) and the error was found and no relationship between $F_{\mathrm{r}-}$ and the error was found. This is consistent with dense soils, where it is hypothesised that grain breakage and dilation may occur during cone penetration [19] and thin films of water may exist between grains, affecting the thermal conductivity result.

Figure 9 shows updated plots, with values of thermal conductivity for soils showing a high $Q_{\mathrm{tn}}$ (over 170) modified via:

$$
\begin{aligned}
k_{\text {soil }}= & k_{\text {soil_orig }}, \quad \text { if } Q_{\mathrm{tn}} \leq Q_{\mathrm{tn} \_l \mathrm{lim}} \\
k_{\text {soil_} \_ \text {updated }}= & k_{\text {soil_orig }}-a \log \left(Q_{\mathrm{tn}} / Q_{\mathrm{tn} \_l i m}\right), \\
& \text { if } Q_{\mathrm{tn}}>Q_{\mathrm{tn} \_l i m}
\end{aligned}
$$

where $k_{\text {soil_orig }}$ is the $k_{\text {soil }}$ predicted by the original relationships, either Eq. (8) or (11), $Q_{\mathrm{tn} \_l i m}$ is the limit of $Q_{\mathrm{tn}}$ where the CPT correlations over-predict the thermal conductivity and $a$ is a fitting coefficient, which has been estimated between 1.5 and 3.0 here ( $a=1.7$ in Fig. 9). The value of $Q_{\mathrm{tn} \_ \text {lim }}$ is judged to be between 100 and 200, with the lower value fitting best the CPT data collected as part of this field campaign and a higher value fitting the sandy soils parts of the CPTs from the database. The RMSE is seen to improve from 0.53 and 0.67 to 0.45 and 0.48 for the $\mathrm{k}-\mathrm{CPT}_{R}$ and the k-CPT ${ }_{L}$ correlations, respectively. The $R^{2}$ values improve from 0.63 and 0.74 to 0.66 and 0.76 for the $\mathrm{k}-\mathrm{CPT}_{R}$ and $\mathrm{k}-\mathrm{CPT}_{L}$ correlations, respectively. This is comparable to the accuracy of the theoretical relationships [10]. The complete correlation, therefore, contains both the theoretical part and this high cone resistance adjustment.

Figure 10 shows two selected CPT profiles including the correlations against the laboratory results. It is noted that the T-CPT results for the thermal conductivity shown in Fig. 10a are the same as those presented for Location 4 in Fig. 13(d) in Vardon et al. [32]. A good match between the thermal conductivity from the T-CPTs and volumetric heat (a)

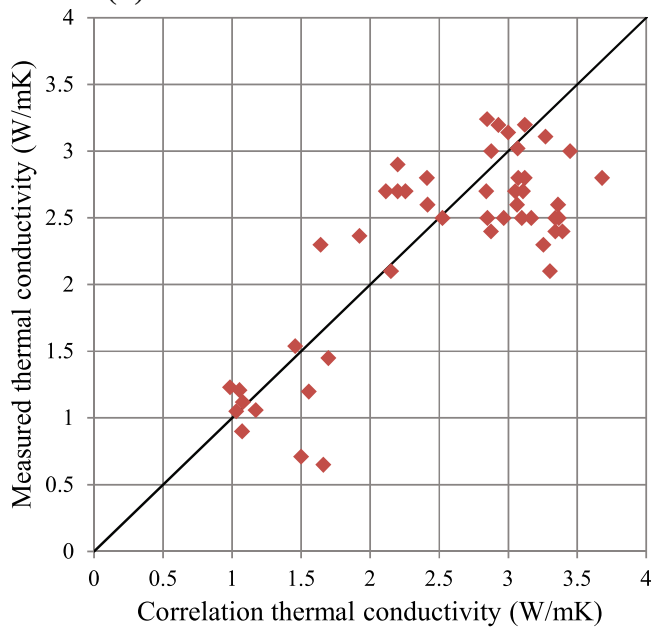

(b)

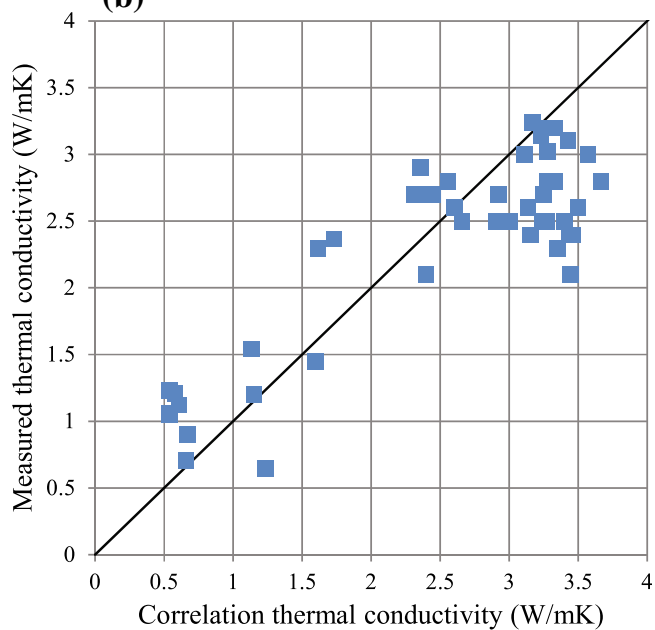

Fig. 8 Comparison of thermal conductivity derived from T-CPT dissipation test data and CPT correlations a theoretical part of k-CPT ${ }_{R}$ correlation $(\mathrm{RMSE}=0.53)$ and $\mathbf{b}$ theoretical part of $\mathrm{k}-\mathrm{CPT}_{L}$ correlation $(\mathrm{RMSE}=0.67)$ 
(a)

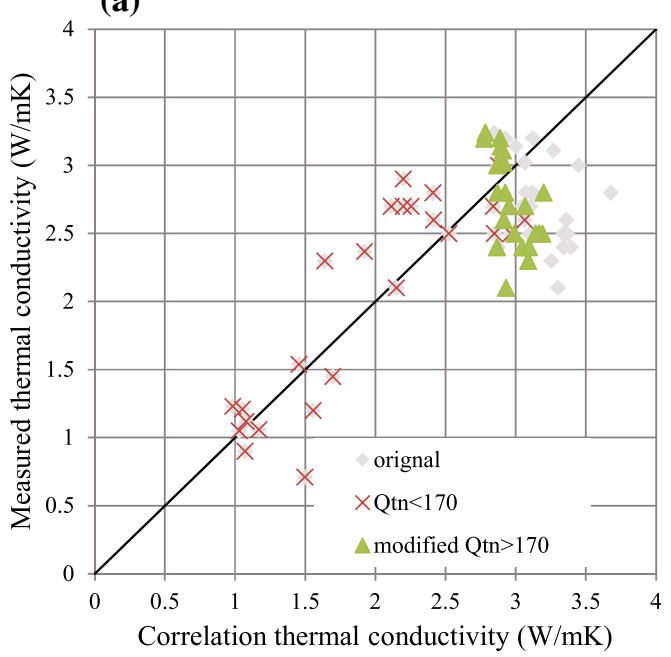

(b)

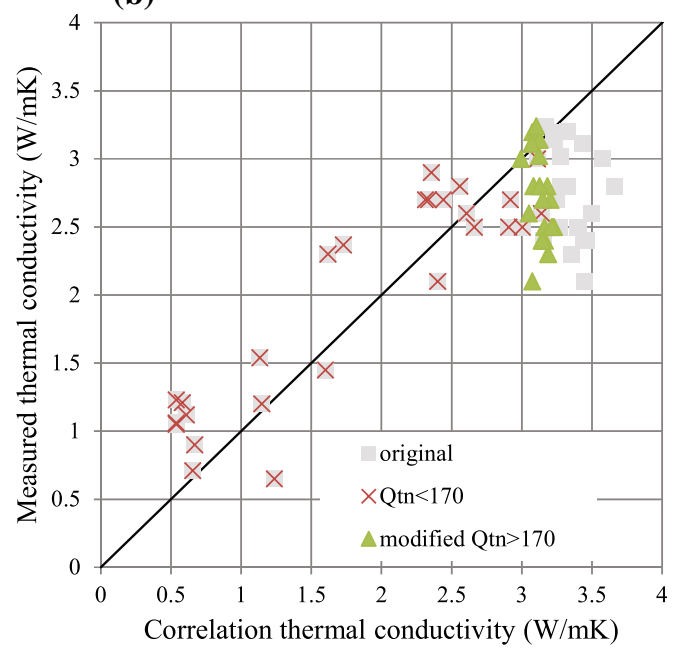

Fig. 9 Illustration of high cone resistance adjustment of thermal conductivity a complete k-CPT ${ }_{R}$ correlation $(\mathrm{RMSE}=0.45)$ and $\mathbf{b}$ complete k-CPT ${ }_{L}$ correlation. $Q_{\mathrm{tn} \_l i m}=170$ and $a=1.7(\mathrm{RMSE}=0.48)$

capacity from the hot disc test and the proposed correlations is seen. There are only limited volumetric heat capacity data on this figure due to the difficulties in collecting in situ volumetric heat capacity, but this figure serves to demonstrate the range of values predicted and the transformation from CPT data to thermal properties.

\section{Discussion}

The proposed correlations for volumetric heat capacity and thermal conductivity are based on correlations that provide important, but not all, features for accurately deriving thermal properties of soils. These correlations are inevitably incomplete and implicitly contain errors and uncertainties which can be broadly estimated but cannot be fully calculated via analysis of the accuracy of the measurement equipment. Comparisons with data obtained otherwise can provide confidence in the method, in this case comparison with data derived from sampled material tested in the laboratory and data derived from in situ tests. All sampling processes disturb the soil samples, thereby inducing errors in that process. This means that a moderate error in the comparison between the results is unavoidable.

Comparison with results from laboratory hot disc tests for volumetric heat capacity showed a low error (RMSE of around 0.06) and a high correlation $\left(R^{2}\right.$ of around 0.7). However, the range of soils tested was small, and the values were corrected for densities. The low error also fits into the finding that many soil minerals have a similar volumetric heat capacity, and therefore identifying the soil type accurately is not essential (see Fig. 1a, and associated text). Further field tests are warranted to confirm the findings on a larger range of soil types.

For the volumetric heat capacity correlations, both show a decrease in volumetric heat capacity with an increase in normalised cone resistance (due to increases in predicted density). In addition, for relatively high values of normalised cone resistance $\left(Q_{\mathrm{tn}}>Q_{\mathrm{tn}, \mathrm{ref}}=50\right)$ the two correlations also both show a decrease in volumetric heat capacity with an increase in normalised friction ratio (probably mainly due to increased over-consolidation ratios and therefore density). However, for soils at relatively low values of normalised cone resistance $\left(Q_{\mathrm{tn}}<Q_{\mathrm{tn}, \mathrm{ref}}=50\right)$ the two correlations give opposing trends for volumetric heat capacity in relation to normalised friction ratio. This is probably due to the interplay between changing composition, changing density and changing OCR or soil structure which changes the normalised friction ratio [28]. It is noted that the underlying Lengkeek et al. [20] density correlation has been shown to be more accurate at relatively low values of normalised cone resistance.

For thermal conductivity, the mineral type plays an important role (see Fig. 1b). Moreover, the arrangement of particles plays a more important role in thermal conductivity and contributes to uncertainties and errors. A structural error is observed at high densities, which has been corrected, although the correction is likely to be soil/site dependent. It is clear from the RMSE (of around 0.5, after correction) that a significant scatter still exists. The values are scattered around the 1:1 line without systematic bias in Fig. 9, i.e. no systematic over or under-prediction, which suggests that the method is accurate, but not precise (relatively high $R^{2}$ and RMSE). Vardon et al. [32] indicated 

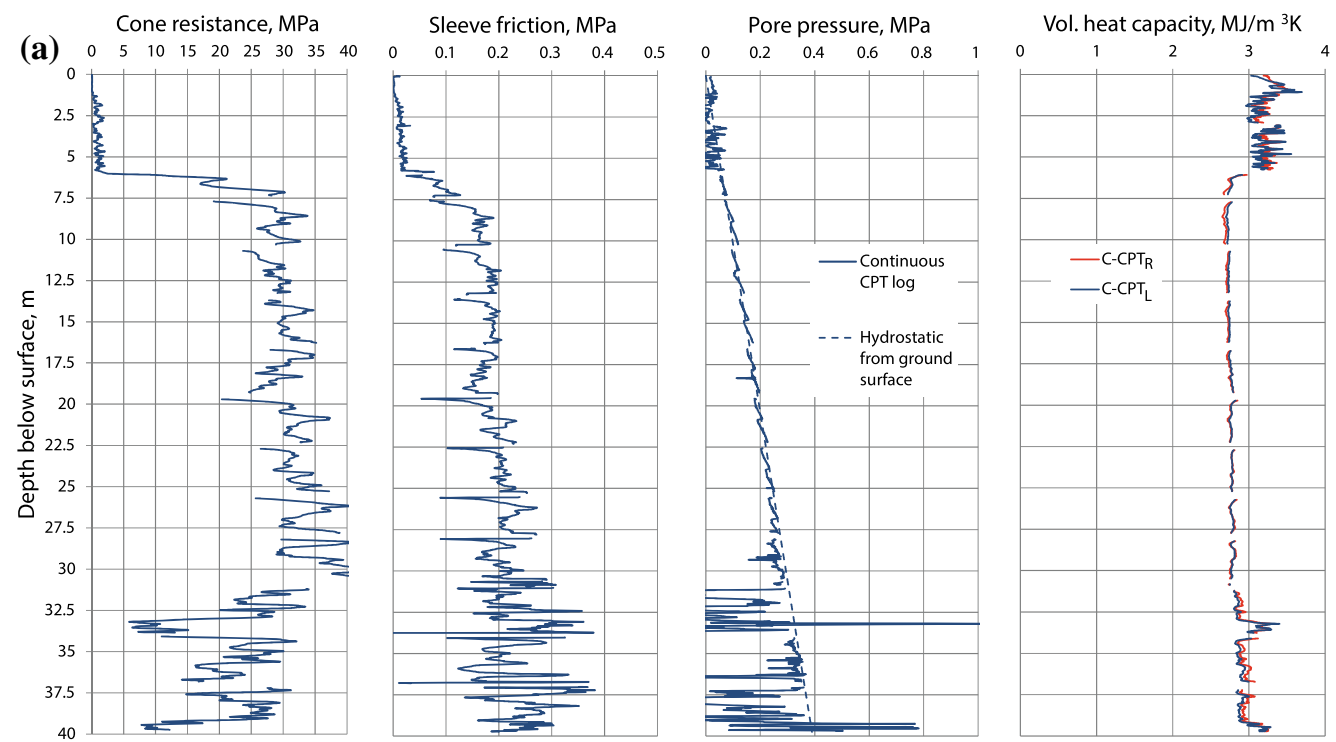

Thermal conductivity, $\mathrm{W} / \mathrm{mK}$
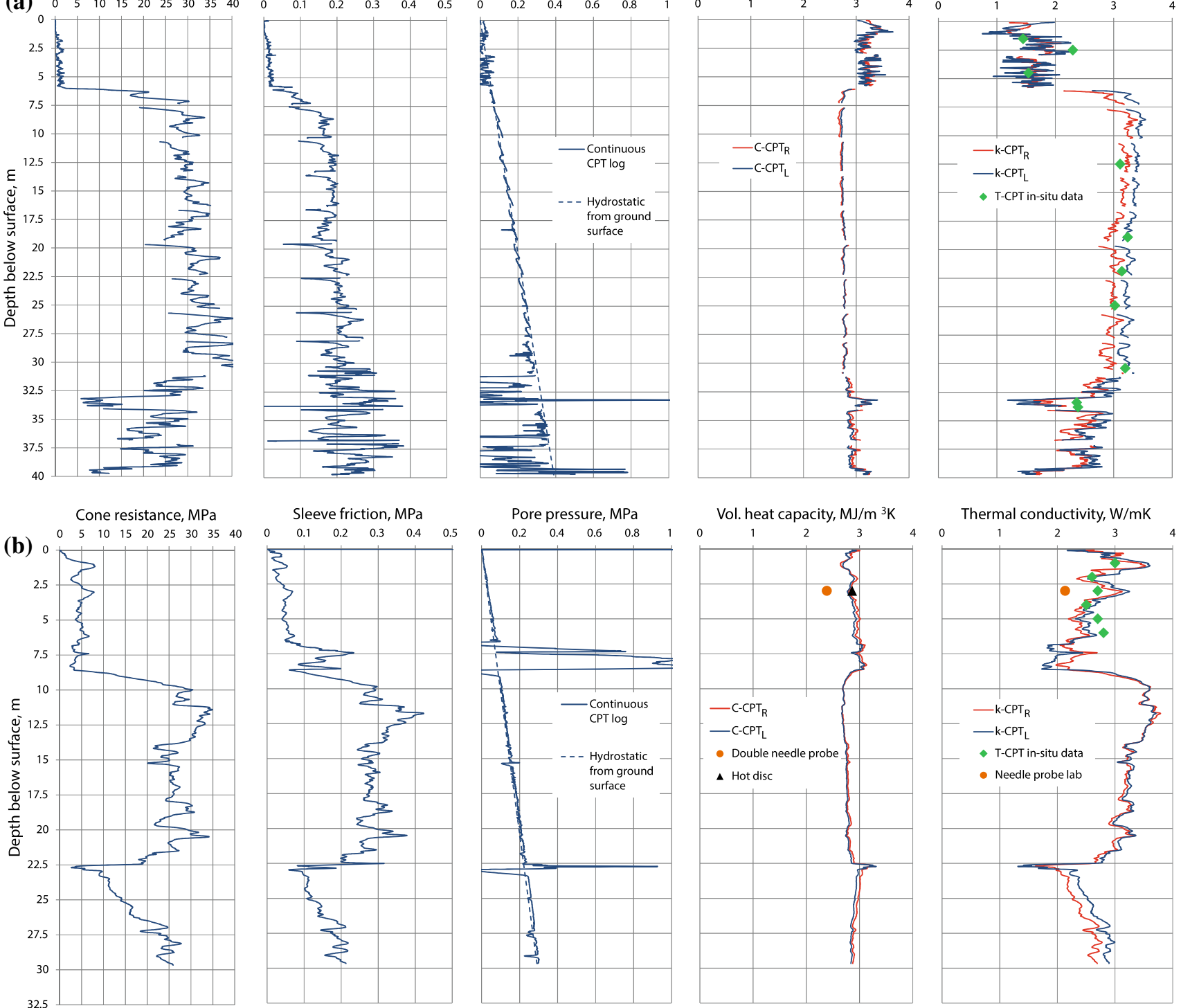

Fig. 10 Two CPT profiles including proposed correlations; the thermal conductivity correlations are both using the high cone resistance correction, with $Q_{\mathrm{tn} \_ \text {lim }}=170$ and $a=1.7$

that point-wise thermal conductivity was shown to be both accurately and precisely determined, whereas the volumetric heat capacity was not. Together the thermal conductivity correlation and point-wise results offer the opportunity of both accurate and precise estimation of thermal conductivity.

\section{Conclusions}

Thermal properties of soil that are representative of in situ conditions are difficult to obtain. CPT correlations for thermal properties have been proposed, which make use of the characteristics of existing CPT correlations, which offer continuous profiles of thermal conductivity and volumetric heat capacity of saturated soil. The continuous estimations provide added value in practice, where previously only point-wise in situ measurements of the thermal conductivity and volumetric heat capacity were available.

A validation of the proposed correlations with field and laboratory tests has been carried out. The volumetric heat capacity CPT correlations proved to match well with hot disc laboratory tests (RMSE around 0.06), whereas the thermal conductivity correlations offered a good match with in situ results (T-CPT and in situ needle probe), with some spread in the results (RMSE around 0.5). An empirical adjustment is needed as part of the thermal conductivity correlations at high cone resistance values. 
Any improvements made in CPT correlations for density can be incorporated in these thermal correlations, following the method given here. Utilising the T-CPT results to provide site-specific adjustment, particularly at high cone resistance values, can give reasonable site-specific profiles.

The strength of this proposed method is that continuous profiles are estimated. This means that differences in thermal properties between layers and sub-layers can be identified and perhaps also targeted for further site investigation. The method proposed in this paper is cost-effective, being that it uses information that is already typically collected during site investigations. It can therefore also be used on existing data, offering a method to produce good initial estimates.

Funding The funding of this work and provision of all experimental data by Fugro are gratefully acknowledged.

\section{Compliance with ethical standards}

Conflict of interest Both authors declare that they have no conflict of interest.

Open Access This article is licensed under a Creative Commons Attribution 4.0 International License, which permits use, sharing, adaptation, distribution and reproduction in any medium or format, as long as you give appropriate credit to the original author(s) and the source, provide a link to the Creative Commons licence, and indicate if changes were made. The images or other third party material in this article are included in the article's Creative Commons licence, unless indicated otherwise in a credit line to the material. If material is not included in the article's Creative Commons licence and your intended use is not permitted by statutory regulation or exceeds the permitted use, you will need to obtain permission directly from the copyright holder. To view a copy of this licence, visit http://creativecommons. org/licenses/by/4.0/.

\section{References}

1. Abu-Hamdeh NH, Reeder RC (2000) Soil thermal conductivity: effects of density, moisture, salt concentration and organic matter. Soil Sci Soc Am J 64(4):1285-1290

2. Akrouch GA, Briaud J-L, Sanchez M, Yilmaz R (2016) Thermal cone test to determine soil thermal properties. J Geotech Geoenviron Eng 142(3):04015085

3. ASTM (2014) D 5334-14 Standard test method for determination of thermal conductivity of soil and soft rock by thermal needle probe procedure. ASTM

4. Brandl H (2006) Energy foundations and other thermo-active ground structures. Géotechnique 56(2):81-122

5. Bromley LA, Desaussure VA, Clipp JC, Wright JS (1967) Heat capacities of sea water solutions at salinities of 1 to $12 \%$ and temperatures of $2{ }^{\circ} \mathrm{C}$ to $80{ }^{\circ} \mathrm{C}$. J Chem Eng Data 12(2):202-206

6. Decagon Devices (2016) KD2 Pro thermal properties analyzer: operator's manual. Decagon Devices, Pullman
7. Di Donna A, Cecinato F, Loveridge F, Barla M (2017) Energy performance of diaphragm walls used as heat exchangers. Proc Inst Civ Eng Geotech Eng 170(3):232-245

8. Farouki OT (1981) Thermal properties of soils. Cold Regions Science and Engineering Laboratory Monograph 81-1, US Army Corps of Engineers

9. Gao Z, Lenschow DH, Horton R, Zhou M, Wang L, Wen J (2008) Comparison of two soil temperature algorithms for a bare ground site on the Loess Plateau in China. J Geophys Res 113:D18105

10. Haigh SK (2012) Thermal conductivity of sands. Géotechnique 62(7):617-625

11. Hamdhan IN, Clarke BG (2010) Determination of thermal conductivity of coarse and fine sand soils. In: Proceedings of the world geothermal congress, paper no 2952

12. Hansen J, Neuhaeuser S, Yesiller N (2004) Development and calibration of a large-scale thermal conductivity probe. Geotech Test J 27(4):393-403

13. Isdale JD, Morris R (1972) Physical properties of sea water solutions: density. Desalination 10(4):329-339

14. ISO (2015) ISO22007-2: Plastics-determination of thermal conductivity and thermal diffusivity — part 2: transient plane heat source (hot disc) method. ISO

15. Ivaev ON, Sharafutdinov RF, Volkov NG, Minkin MA, Dmitriev GY, Ryzhkov IB (2018) New Russian standard CPT application for soil foundation control on permafrost. In: Proceedings of the 4th international symposium on cone penetration testing (CPT'18), pp 359-363

16. Jefferies MG, Davies MP (1993) Use of CPTu to estimate equivalent SPT $\mathrm{N}_{60}$. Geotech Test J ASTM 16(4):458-468

17. Jia GS, Tao ZY, Meng XZ, Ma CF, Chai JC, Jin LW (2019) Review of effective thermal conductivity models of rock-soil for geothermal energy applications. Geothermics 77:1-11

18. Johansen O (1975) Varmeledningsevne av jordarter. Group for thermal analysis of frost in the ground. Institute for Kjoleteknikk [Translation (1977): Draft Translation 637, Cold Regions Science and Engineering Laboratory, US Army Corps of Engineers]

19. Konrad J-M (1998) Sand state from cone penetrometer tests: a framework considering grain crushing stress. Géotechnique 48(2):201-215

20. Lengkeek HJ, de Greef J, Joosten S (2018) CPT based unit weight estimation extended to soft organic soils and peat. In: Proceedings of the 4th international symposium on cone penetration testing (CPT'18), pp 389-394

21. Limberger J, Boxem T, Pluymaekers M, Bruhn D, Manzella A, Calcagno P, Beekman F, Cloetingh S, van Wees J-D (2018) Geothermal energy in deep aquifers: a global assessment of the resource base for direct heat utilization. Renew Sustain Energy Rev 82(1):961-975

22. Low JE, Loveridge FA, Powrie W, Nicholson D (2015) A comparison of laboratory and in situ methods to determine soil thermal conductivity for energy foundations and other ground heat exchanger applications. Acta Geotech 10(2):209-218

23. McCallum A (2014) A brief introduction to cone penetration testing (CPT) in frozen geomaterials. Ann Glaciol 55(68):7-14

24. Netherlands Enterprise Agency (2019) Report-seafloor in situ test locations HKN-Fugro. https://offshorewind.rvo.nl/file/view/ 55040044/Report+-+Seafloor+In+Situ+Test+Locations+HKN++Fugro

25. Raymond J (2018) Colloquium 2016: assessment of subsurface thermal conductivity for geothermal applications. Can Geotech J 55(9):1209-1229

26. Rerak M, Ocłoń $P$ (2017) Thermal analysis of underground power cable system. J Therm Sci 26(5):465-471

27. Robertson PK (1990) Soil classification using the cone penetration test. Can Geotech J 27(1):151-158 
28. Robertson PK (2016) Cone penetration test (CPT)-based soil behaviour type (SBT) classification system-an update. Can Geotech J 53(12):1910-1927

29. Robertson PK, Cabal KL (2015) Guide to cone penetration testing for geotechnical engineering, 6th edn. Gregg Drilling and Testing

30. TNO (2019) Thermal conductivity, density and volumetric heat capacity of soil samples. TNO report no. TNO 2019 M10298 to Fugro

31. van Wijk WR (ed) (1963) Physics of plant environment, 1st edn. North Holland, Amsterdam

32. Vardon PJ, Baltoukas D, Peuchen J (2019) Interpreting and validating the Thermal Cone Penetration Test (T-CPT). Géotechnique 69(7):580-592. https://doi.org/10.1680/jgeot.17.P.214
33. Vieira A, Maranha J, Alberdi-Pagola M, Christodoulides P, Javed S, Loveridge F, Nguyen F, Cecinato F, Maranha F, Florides G, Prodan I, van Lysebetten G, Ramalho E, Salciarini D, Georgiev A, Rosin-Paumier S, Popov R, Lenart S, Erbs Poulsen S, Radioti G (2017) Characterisation of ground thermal and thermo-mechanical behaviour for shallow geothermal energy applications. Energies, MDPI 10(12):2044

Publisher's Note Springer Nature remains neutral with regard to jurisdictional claims in published maps and institutional affiliations. 